\title{
RESPONSABILIDAD PENAL DE LAS PERSONAS JURÍDICAS: ¿NUEVA ERA COMPLIANCE EN ECUADOR? UN DIÁLOGO CON ESPAÑA ${ }^{\mathrm{I}}$ \\ Corporate Criminal Liability: A New Era of Compliance in Ecuador?
} A Dialogue with Spain

\author{
Alfredo Liñán Lafuente ${ }^{2}$ \\ Universidad Nacional de Educación a Distancia, Madrid, España \\ José Roberto Pazmiño Ruiz \\ Universidad Complutense de Madrid, Madrid, Espańa
}

\section{Resumen}

La reciente modificación de la ley penal ecuatoriana ha generado variadas interpretaciones respecto a la responsabilidad penal de la persona jurídica. En este artículo se plantean diversas cuestiones que deberán ser abordadas por la justicia ecuatoriana en un futuro cercano, tales como el modelo de responsabilidad penal de la persona jurídica, su fundamento político-criminal y dogmático, la importancia del compliance y, especialmente, su interpretación a la luz de la Constitución. En España ya se han planteado estas cuestiones y el Tribunal Supremo ha sentado doctrina al respecto. Este artículo pretende establecer un diálogo entre las dos jurisdicciones para que la experiencia acumulada de la doctrina y jurisprudencia de ambas pueda ser mutuamente provechosa.

\section{Palabras clave}

Responsabilidad penal de las personas jurídicas, programas de cumplimiento, interpretación constitucional, derecho penal ecuatoriano, derecho penal espańol.

\footnotetext{
Abstract

The recent amendment to the Ecuadorian criminal code has generated varied interpretations regarding corporate criminal liability. This paper raises various issues that will have to be addressed by the Ecuadorian justice system in the near future, such as the model of corporate criminal liability, its political-criminal and dogmatic basis, the importance of compliance and, especially, its interpretation in light of the Constitution. In Spain, these issues have already been raised and the Supreme Court has established case law on the subject. This

${ }^{1}$ Los autores de este artículo han contribuido en partes iguales.

2 Doctor en Derecho por la Universidad Complutense de Madrid. Profesor del Departamento de Derecho Penal y Criminología de la Universidad Nacional de Educación a Distancia. Académico Correspondiente de la Real Academia de Jurisprudencia y Legislación de España. Consultor académico del despacho Ollé Sesé Abogados. Correo electrónico: alinan@der. uned.es; ORCID: https://orcid.org/0000-0003-1735-3884.

${ }^{3}$ Abogado por la Universidad Católica de Santiago de Guayaquil. Máster en Derecho Penal por la Universidad de Salamanca. Máster en Derecho Penal económico por la Universidad Rey Juan Carlos. Postgrado en Compliance por la Universidad Carlos III y Pompeu Fabra. Doctorando en Derecho por la Universidad Complutense de Madrid. Correo electrónico: jroberto.pazmino@gmail.com; ORCID: https://orcid.org/0000-0003-0275-2057.

Agradecimientos a Victoria Pinta por la recolección de la bibliografía ecuatoriana y a Juan Francisco Pozo Torres por sus observaciones.
} 
article aims to establish a dialogue between the two jurisdictions so that their accumulated experience of legal theory and case law can be mutually beneficial.

\section{Keywords}

Corporate Criminal Liability, Compliance Programs, Constitutional Interpretation, Ecuatorian Criminal Law, Spanish Criminal Law.

\section{Introducción}

Desde la vigencia del Código Orgánico Integral Penal (en adelante COIP) de 2014 se ha convertido en lugar común de la doctrina ecuatoriana aceptar que el principio societas delinquere non potest ha sido derrumbado por el legislador: la imposibilidad dogmática ha cedido ante la "necesidad" político-criminal ${ }^{4}$. Voces vanguardistas (Basabe Serrano, 2003) reclamaban además con cierta anterioridad una auténtica responsabilidad penal de las personas jurídicas (en adelante RPPJ) en Ecuador. Por otro lado, la doctrina española en general no ha sido tan proclive a admitir sin reservas esta tendencia político-criminal, debido a la clásica incapacidad de acción y de culpabilidad de la persona jurídica como barrera dogmática infranqueable, a pesar de que desde el 2010 la RPPJ encuentra acogida en el Código Penal español (en adelante CPe) 5

Sea como fuere, Ecuador ha pasado prontamente la etapa del "sí" para enfocarse en el "cómo" de dicha responsabilidad penal. La llamada ley anticorrupción de 2021 que reforma el COIP se enmarca en esta tendencia ${ }^{6}$. En esta reforma se desarrollan los "requisitos mínimos" de los llamados programas de cumplimiento o compliance $e^{7}$ dotando de contenido a una herramienta que tradicionalmente ha estado alejada del ámbito penal, pero que se configura ahora como un elemento fundamental en la investigación y decisión sobre la RPPJ en el caso concreto.

En España sucedió algo similar. El CPe en 2010 incluyó en su art. 31 bis la RPPJ. En esta primera redacción, el legislador solo se refirió al "debido control" y a su ausencia como un elemento que fundamentaba la RPPJ. Ante las infinitas incógnitas que despertó el término "debido control", el legislador se encargó, en la reforma de 2015, de incluir en el art. 31.bis.5. CPe los contenidos mínimos de un programa de cumplimiento penal y-algo no menos importante- reconocer el efecto exoneratorio de la RPPJ en caso de que se hubieran adoptado con carácter previo a la comisión del delito modelos de organización y gestión que incluyan las medidas de vigilancia y control idóneas para prevenir los delitos o reducir significativamente el riesgo de su comisión (art. 31.bis.2 CPe).

Los paralelos entre la legislación ecuatoriana y española son evidentes ${ }^{8}$. Es más, la legislación española ha sido fuente de inspiración directa para la presidencia en su veto parcial

\footnotetext{
${ }^{4}$ Entre otros, Zavala Egas (2014); Araujo Granda (2014); Zambrano Pasquel (2017); Pozo Torres (2018); Lopez Cobeña (2018).

${ }^{5}$ Críticos, entre otros, Robles Planas (2011); Gómez Martín (2012); Mir Puig (2015); Gracia Martín (2016).

${ }^{6}$ Dicho sea de paso, la Ley de Extinción de Dominio de 2021 se diferencia de la RPPJ por su carácter real, dirigido contra bienes y no contra personas (art. 3, inc. 2), y que además solo sería aplicable en los casos en que una persona jurídica esté involucrada en delitos como cohecho activo (art. 280 COIP), lavado de activos (art. 317 COIP) o trata de personas (art. 91 COIP), al ser estos los únicos delitos dentro del catálogo numerus clausus de RPPJ en el COIP que además se encuentran incluidos en la definición de "actividad ilícita" de la Ley de Extinción de Dominio (art. 7 a)).

${ }^{7}$ Con pretensiones de exhaustividad, el COIP se refiere a "sistemas de integridad, normas, programas y/o políticas de cumplimiento, prevención, dirección y/o supervisión" (arts. 45.7.d), 49).

${ }^{8}$ Desde el enfoque español, Fernández Teruelo (2020, p. 214); desde el ecuatoriano, Lopez Cobeña (2018, p. 94). El infome para primer debate del Proyecto de COIP advertía que las disposiciones eran "transcripciones incipientes del Código Penal español" (2012, p. 22).
} 
a la ley anticorrupción (Presidencia del Ecuador, 2021, p. 1). Por lo tanto, la importancia para Ecuador de mantener un diálogo con Espańa resulta fructífera: un país que se enmarca en similar tradición jurídica y que va afrontando por once años los problemas teóricos y prácticos de la implementación de esta institución. Quizás los errores que se han cometido en España, y que comentaremos en este artículo, sirvan para evitar que Ecuador incurra en los mismos.

\section{Contexto internacional}

Más allá de que en el debate europeo-continental la RPPJ sea vista como uno de los temas estrella de la política criminal de comienzos del siglo XXI (Nieto Martín, 2008, p. 37) ${ }^{9}$, el COIP de 2014 ha omitido referencia expresa a las razones o a cualquier normativa internacional que motive la incorporación de una RPPJ ${ }^{10}$. En todo caso, Ecuador se suma así a la -supuesta- "marcha triunfal del modelo penal" de responsabilidad de las personas jurídicas que sigue acechando a la comunidad internacional (Schünemann, 2014, p. 12).

$\mathrm{Al}$ parecer, las recomendaciones GAFI habrían sido el catalizador de este nuevo régimen en el COIP (así: Páez Bimos, 2017, p. 13): la recomendación 2 advertía -de manera vacilante- que la legislación ecuatoriana "no establece la imputación penal directa de las personas jurídicas" en el delito de lavado de activos, pero "están contempladas sanciones penales subsidiarias a las empresas, inclusive la posibilidad de extinción de la persona jurídica que sea condenada por lavado de activos" (GAFISUD, 2011, pp. 45 s.); esto para finalizar con una calificación "MC" (mayoritariamente cumplido), en la que se concluye que la legislación ecuatoriana permite "la aplicación de sanciones penales eficaces", pero el ámbito "se restringe a las personas jurídicas creadas para el cometimiento del delito de lavado de activos" (pp. 56, 319). Sea como fuere, ampliar la aplicación de las "sanciones penales eficaces" a personas jurídicas en supuestos de lavado de activos no significa instaurar un régimen general de responsabilidad penal para estas, que fue lo que ocurrió en 2014 (vid. nota 9).

Por otro lado, la ley anticorrupción 2021 tomó expresamente en consideración dos normativas internacionales (último considerando). En lo relevante, el art. 26 de la Convención de las Naciones Unidas contra la Corrupción implica tres cuestiones para Ecuador. a) Que cada Estado podrá adoptar según sus principios jurídicos entre una responsabilidad penal, civil, o administrativa de las personas jurídicas (art. 26.2): esto significa que la adopción de una responsabilidad penal fue una decisión político-criminal y no un compromiso internacional. Ecuador pudo haber escogido, con sujeción a sus principios jurídicos (léase: societas delinquere non potest), entre una responsabilidad civil o administrativa, pero optó por la penal ${ }^{11}$. b) Que la responsabilidad de la persona jurídica es acumulativa a la de la persona física (art. 26.3): esto se cumple a través de los arts. 49 inc. 2 y 50 COIP. c) Que las sanciones deben ser

\footnotetext{
${ }^{9}$ Para otros, un "zombi político-criminal" (Schünemann, 2014).

${ }^{10}$ En los textos pre-legislativos se puede advertir una referencia genérica al marco internacional "que se ha tomado en cuenta" (vid. Informe $1^{\circ}$ debate COIP, 2012, pp. 1-30).

${ }^{11}$ Cláusula por lo demás recurrente en la normativa internacional; vid. un dictamen de la Corte Constitucional del Ecuador (027-13-DTI-CC): "Si bien existen Estados que, en sus ordenamientos jurídicos, han adoptado el principio societas delinquere potest, la norma convencional no impone la obligación de establecer la responsabilidad penal de las personas jurídicas por la comisión de los delitos tipificados en el artículo 1, [...] sino que esta medida es optativa ('podrán') y 'de conformidad con sus principios jurídicos nacionales" (2013, pp. 24 s.); y expresamente el comentario de la OCDE al art. 2 sobre la Convención para combatir el cohecho de servidores públicos extranjeros en transacciones comerciales internacionales: "En el caso de que, conforme al régimen jurídico de una Parte, la responsabilidad penal no sea aplicable a las personas morales; no deberá requerírsele a esa Parte que establezca ese tipo de responsabilidad penal" (1997, p. 15).
} 
"eficaces, proporcionadas y disuasivas", incluyendo sanciones monetarias (art. 26.4): ¿cumple con esto Ecuador? (vid. infra).

Por lo visto, la ocasión de la reforma legislativa se debió a algo más concreto: el deseo del Gobierno de mantener contento a su acreedor internacional. Durante la pandemia, el Fondo Monetario Internacional (en adelante FMI) aprobó un acuerdo con Ecuador en el cual permitía un desembolso inmediato de aprox. 30\% del valor total (FMI, 2020b); el resto estaría sujeto a revisiones periódicas (2020a, p. 23). Uno de los temas incluidos (selling points) por Ecuador en su carta de intención fue precisamente la ley anticorrupción (FMI, 2020a, p. 87).

\section{Contexto nacional}

Dentro del debate nacional conviven posiciones descriptivo-expositivas del régimen de RPPJ en Ecuador y posturas en contra ${ }^{12}$. Por otro lado, la literatura especializada se encuentra divida respecto al modelo de responsabilidad seguido por el COIP: ¿responde la persona jurídica por lo realizado por ella (hecho propio) o por lo que hicieron sus miembros (hechos ajenos)? En otras palabras, ¿se sigue un modelo de auto- o de heterorresponsabilidad?

Los que interpretan el modelo como de heterorresponsabilidad -también llamado vicarial, por transferencia, etc.- se basan en la rigurosa literalidad del art. 49: la empresa es responsable por los "delitos cometidos" / "acción u omisión" de las personas físicas ahí descritas; esto es, a la persona jurídica se le transfiere la responsabilidad de la persona física con tal que cumpla con los demás requisitos de conexión (esencialmente, el criterio del beneficio ${ }^{13}$.

Los que defienden un modelo de autorresponsabilidad -también de responsabilidad propia, etc.- se basan mayoritariamente en una interpretación constitucional del precepto: la persona jurídica debe responder no por los hechos de otro (persona física), sino por una conducta propia (principio de culpabilidad) ${ }^{14}$. Como construcción dogmática común se recurre al defecto de organización ${ }^{15}$ como la conducta atribuible a la persona jurídica: esta responde por no organizarse adecuadamente de manera que haya facilitado o incentivado la comisión de delitos en su beneficio por parte de sus miembros. En pocas palabras, la persona jurídica responde por una infracción del deber de control.

Este debate doctrinal es muy similar al que se sigue produciendo en España, aunque las sentencias del Tribunal Supremo (en adelante STS) sobre el particular se inclinan por un modelo de RPPJ que respete el principio de culpabilidad, limitando los intentos de la fiscalía española de deslizarse hacia un modelo vicarial. Y es que, si España y Ecuador han optado por incorporar una RPPJ, lo que no cabe es aplicar formas de responsabilidad por transferencia sin más - por la acción u omisión de otro- que está prohibido en el ámbito del derecho penal a causa del principio de culpabilidad (vid. infra).

En España, tras la reforma de 2015, la Fiscalía General del Estado (en adelante FGE) publicó la Circular $1 / 2016^{16}$ donde se inclinaba por una responsabilidad vicarial, pues

\footnotetext{
${ }^{12}$ En general, vid. García Falconí (2014, pp. 423-436; hay 2a ed.); Albán Gómez (2015, pp. 103-108, 261 s.). En contra: Rodríguez Moreno (2020, pp. 238-245); Encalada Hidalgo (2014, pp. 33 s., 36-39).

${ }^{13}$ Así, vid. López Cobeña (2018, pp. 105 s., 130); Pacheco (2019, pp. 189 s., 217); Mila (2020, pp. 154 s.).

${ }^{14}$ Así, vid. Zavala Egas (2014, pp. 82-93); Raza Castañeda (2016, pp. 240-247); Pozo Torres (2018, pp. 76-92). Similar: Araujo Granda (2014, pp. 76-80); García Falconí y Alba Zurita (2017, pp. 375 s., 393 s.); Páez Bimos (2017, p. 8; 2021, p. 114); Araujo Correa et al (2019, p. 292); Zambrano Pasquel (2021, passim).

${ }^{15}$ Introducido en 1988 en la discusión alemana por Tiedemann (cfr. 1996, p. 116; 2010, párr. 244a).

${ }^{16}$ Las circulares de la FGE no tienen naturaleza jurisdiccional y no vinculan a los jueces, pero sirven como pautas interpretativas que han de seguir los fiscales en su actuación profesional.
} 
obviamente es más fácil de usar para la acusación, ya que con demostrar la responsabilidad de la persona física, la de la persona jurídica le sigue en cadena si concurren los elementos de atribución (el beneficio, el cargo y el actuar en el ámbito de la actividad empresarial); aunque también se reconocía en la citada Circular el valor exoneratorio del compliance ex ante, por lo que introdujo un matiz importante en dicha interpretación.

Por el contrario, el Tribunal Supremo español desde una sentencia precursora exigía el respeto a los principios irrenunciables del Derecho penal (como el principio de culpabilidad) en materia de RPPJ ${ }^{17}$. La tendencia ha sido interpretar que la responsabilidad de la persona jurídica deviene de una conducta propia -distinta de la de la persona física-, utilizando la teoría del defecto de organización como fundamento de su responsabilidad ${ }^{18}$. En este sentido, la STS 221/2016, de 16 de marzo, recuerda a la fiscalía que:

\begin{abstract}
En definitiva, en la medida en que el defecto estructural en los modelos de gestión, vigilancia y supervisión constituye el fundamento de la responsabilidad del delito corporativo, la vigencia del derecho a la presunción de inocencia impone que el Fiscal no se considere exento de la necesidad de acreditar la concurrencia de un incumplimiento grave de los deberes de supervisión. Sin perjuicio de que la persona jurídica que esté siendo investigada se valga de los medios probatorios que estime oportunos -pericial, documental, testifical- para demostrar su correcto funcionamiento desde la perspectiva del cumplimiento de la legalidad (Tribunal Supremo español, 2016, p. 35).
\end{abstract}

\title{
3.1. Pronunciamientos jurisdiccionales en Ecuador
}

Uno de los primeros pronunciamientos de las altas esferas jurisdiccionales después de instaurada la RPPJ en Ecuador fue una sentencia de la Corte Constitucional de 2018 (001-18-SIN-CC $)^{19}$. En ella se discutía la constitucionalidad por reserva de ley del régimen del art. 49 del COIP y violación del principio de igualdad al excluirse a las personas jurídicas de derecho público del régimen de responsabilidad penal. La Corte negó la inconstitucionalidad (p. 22). En lo relevante, la sentencia afirma que las personas jurídicas de derecho privado "nacen a partir de la voluntad de sus asociados", con fines de lucro (a excepción de las asociaciones y fundaciones) y "a efectos de dedicarse a una actividad -civil o mercantil- que en último persigue un beneficio de los asociados" ${ }^{20}$; mientras que las de derecho público nacen de la Constitución, la ley o de un acto del poder público "destinadas a satisfacer las necesidades del interés general, a través del ejercicio de la administración pública" (p. 20). Por ello, solo las personas jurídicas de derecho privado "pueden ser constituidas o utilizadas con el objeto de perpetrar una infracción”; en cambio, en las de derecho público implicaría que el propio Estado se autoimponga una sanción (el Estado no ejerce el ius puniendi contra sí mismo), lo cual resulta incompatible con la finalidad de satisfacer el interés general (pp. 21 s.).

\footnotetext{
${ }^{17}$ STS 514/2015, de 2 de septiembre: "[...] ya se optara por un modelo de responsabilidad por el hecho propio, ya por una fórmula de heterorresponsabilidad, parece evidente que cualquier pronunciamiento condenatorio de las personas jurídicas habrá de estar basado en los principios irrenunciables que informan el derecho penal".

${ }^{18}$ Sobre esto, vid. SSTS: 154/2016, de 29 de febrero; 221/2016, de 16 de marzo; 827/2016, de 3 de noviembre; 121/2017, de 23 de febrero; 260/2017, de 6 de abril; 455/2017, de 21 de junio de 2017; 583/2017, de 19 de julio; 668/2017, de 11 de octubre de 2017.

${ }^{19}$ Anterior al COIP: 027-13-DTI-CC (pp. 5-23).

${ }^{20}$ Puede ser esta la razón por la cual el COIP equipara el beneficio propio de la empresa con la de sus asociados, mas si se intenta beneficiar a un tercero se excluye la responsabilidad (art. 49 últ. inc.).
} 
Interesante de cara a una interpretación teleológica, la Corte afirma que el régimen de RPPJ "persigue un fin constitucionalmente válido", a saber:

[...] tutelar los derechos catalogados como bienes jurídicos protegidos; garantizar la reparación integral de las víctimas a través de la sanción a los responsables -personas naturales y jurídicas-; y, evitar la impunidad a través del desarrollo del proceso penal como medio para la realización de la justicia $[\ldots](2018$, p. 21$)$

Hasta donde se ve, la Corte Nacional de Justicia no se ha pronunciado al respecto. Empero, no ha sido por falta de oportunidad, ej.: juicio no $17282-2017-03592^{21}$. En primera instancia, se condena como autora directa (art. 42.1.a) COIP) de defraudación tributaria tanto a la persona física (gerente) como a la jurídica, a esta última sin motivación alguna. En apelación, se ratifica la inocencia de ambas y se corrige al tribunal a quo al afirmar que la autoría directa solo puede atribuirse "por definición conceptual" a una persona física; en cambio, a la persona jurídica le es de aplicación el régimen del art. 49 COIP, pues la participación de estas "deriva del beneficio otorgado por esa persona natural" (Corte Provincial de Pichincha, 2019 , p. 8). Se niega la casación a la acusación particular (SRI), mas la Corte Nacional no se pronuncia sobre dicho régimen.

\section{Propuesta de interpretación}

Es cierto que una lectura sin preconcepciones interpretativas del art. 49 COIP sugiere que el legislador ecuatoriano ha optado por un modelo vicarial ${ }^{22}$, ya que la RPPJ surge de la comisión de un hecho delictivo por alguna de las personas físicas ahí indicadas, sin que se contemple la posibilidad de eximir a la persona jurídica si hubo un delito en su beneficio; empero, no es menos cierto que también conviven rasgos del modelo de autorresponsabilidad (vid. infra).

En todo caso, cualquier interpretación en materia penal debe realizarse "en el sentido que más se ajuste a la Constitución” (art. 13.1 COIP; también, Zavala Egas, 2014, p. 70). Además de que cualquier modelo de RPPJ debe ser coherente con la finalidad político-criminal que persiga el Estado con la implementación de esta institución.

A continuación, se desarrollarán estos argumentos que desembocan en la defensa de un modelo mixto tendiente a la autorresponsabilidad (o modelo de autorresponsabilidad mínima) por estar en mejores condiciones no solo para responder a los desafíos constitucionales en Ecuador con fundamento en los principios del derecho penal -sobre todo por la excesiva severidad de las penas aplicables a la persona jurídica y la falta de una exclusión expresa de responsabilidad- sino también porque un modelo así es más aconsejable político-criminalmente.

\subsection{Argumento político-criminal -económico-}

[...] el cumplimiento de la ley, mediante la adopción trascendental de una legislación anticorrupción antes de fin de año, protegería las arcas públicas, catalizaría la inversión privada, promovería la creación de empleo e impulsaría el potencial de crecimiento. (FMI, 2020b, Comunicado de Prensa no 20/302)

\footnotetext{
${ }^{21}$ Sobre la praxis comentan críticamente Páez Bimos (2017, p. 7) y Zambrano Pasquel (2021, pp. 8 s.).

22 En el debate español, Silva Sánchez (2016, pp. 331 ss.); similar, Pozo Torres (2018, pp. 76 ss.).
} 
Si Ecuador ha llegado a un acuerdo con el FMI para reactivar la economía (vid. supra), ¿estaría fomentando dicho fin si la sanción penal predilecta para las empresas es la extinción/disolución + multa (según el cómputo de la parte especial)? ¿no será un exceso sancionar tan severamente a la persona jurídica sin que esta pueda alegar un debido control? ¿`se ha tenido en cuenta a los trabajadores/directivos que no cometieron el delito y que se verán perjudicados por el cierre de la empresa? Una de las lecciones más importantes sobre ello nos lo ofrece el caso Enron, que provocó la quiebra tanto de la empresa como de la auditora Arthur Andersen (una de las cinco grandes a nivel mundial); miles de personas se quedaron sin trabajo. A partir de ese momento, en EE. UU. se abrió una tercera vía para tomar en cuenta -entre otros- el daño a terceros inocentes: se daba preferencia a los acuerdos de no persecución o de persecución diferida (Non-/Deferred Prosecution Agreement) con la Fiscalía en supuestos de RPPJ ${ }^{23}$.

Dos son los problemas político-criminales de un modelo como el vicarial que no toma en cuenta la conducta empresarial y pone el foco únicamente en la comisión del delito individual: a) a veces no es fácil individualizar a la persona física que cometió del delito; b) provoca que la empresa trate de ocultar el delito individual, pues sabe que no tiene otra defensa posible (Nieto Martín, 2015, pp. 112-117). En suma, en el modelo vicarial, la suerte de la persona física y jurídica van de la mano, lo cual genera que la empresa tenga poco interés en adoptar un programa de cumplimiento: ¿cuál es el incentivo para instaurar un compliance si se va a responsabilizar de todos modos a la empresa? Un programa de cumplimiento idóneo no es sinónimo de prevención absoluta, sino de una prevención razonable de delitos. En definitiva, el riesgo cero de incumplimiento empresarial no existe y es imposible prever los distintos factores que pueden provocar la comisión de un delito por una persona física. Lo más que puede hacer la persona jurídica es identificar los focos de peligro de su actividad y controlar que estos se mantengan dentro del riesgo permitido.

Otro problema práctico: ¿son las sanciones penales contra empresas eficaces, proporcionadas y disuasivas (locución internacional recurrente)? La frase interpela a que las sanciones deban concretarse en plano material (aplicarse), guarden relación con la gravedad de la infracción, y desalienten o cambien el comportamiento futuro de sus destinatarios. Si bien los Estados tienen un amplio margen para plasmar la normativa internacional en su ordenamiento interno, es dudoso que el COIP cumpla desde su literalidad con alguna de estas características. a) Las sanciones no son eficaces, debido a que en la mayoría de los casos los jueces deberán decidir entre dos grandes extremos: la extinción/disolución + multa $o$ la inocencia de la empresa, lo cual genera mayores reparos en su aplicación judicial ${ }^{24}$. b) Debido a este todo o nada, las sanciones tampoco son proporcionales -a excepción de la multa y prima facie la clausura ${ }^{25}$-: no importa si se trata de una empresa criminal, promedio (neutral) o con

\footnotetext{
${ }^{23}$ Vid. más en detalle Koehler (2015, pp. 500-515); Villegas García (2015, pp. 315-326); Sun Beale (2016).

${ }^{24}$ Incluso cuando Ecuador juegue con otra variable relevante en la praxis: el aparente desconocimiento del nuevo régimen (cfr. nota 19) hace que por un lado se generen automatismos en la RPPJ (sanción "sí o sí" a la empresa) y por otro que decaigan acusaciones por violaciones burdas a la normativa sustantiva o procesal. En definitiva, todo depende de quién se beneficie de ese desconocimiento.

${ }^{25}$ Cfr. art. 71.3. COIP: "Clausura temporal o definitiva [...], según la gravedad de la infracción o del daño causado". Empero, no es el juez quien decide, sino que el legislador ha decidido previamente la sanción de cada delito en concreto (concuerda, Araujo Granda, 2014, p. 89). Por ello, hubiese sido preferible que la clausura -al igual que la extinción, etc.sea una de las sanciones facultativas a imponer por el juez dependiendo de su necesidad en el caso particular (similar al caso español: art. 66 bis. CPe).

En los casos en que se deba imponer una clausura temporal como sanción y no se fije un límite de tiempo (arts. 218, 258.1. y 2. COIP), esta no debería exceder la pena de prisión de la persona física (siguiendo el criterio del art. 247 penúltimo inc.). Con todo, una sanción indeterminada como esta difícilmente respeta el nulla poena sine lege certa (prohibición de sanciones penales indeterminadas: arts. 54 COIP, 76.3. CRE).
} 
una "cultura ética", si se cometió un delito en su beneficio por una de las personas vinculadas a la empresa, responderán todas de la misma manera -incluso si hay atenuantes-, pues ¿̨cómo se modulalatenúa una extinción/disolución? ${ }^{26}$ c) A consecuencia de lo anterior, las sanciones tampoco son disuasivas: a la empresa "le sale lo mismo" intentar prevenir delitos que no hacerlo, contar con un programa de cumplimiento que no tenerlo. En definitiva, no se fomentaría un cambio de comportamiento en el ámbito empresarial ecuatoriano ${ }^{27}$.

Desde Beccaria conocemos que los delitos no se previenen endureciendo las penas, sino asegurando su pronta detección y castigo. En el caso de Ecuador, la severidad debido a la falta de modulación de las sanciones empresariales, acompañada de la ausencia expresa de una causa de exclusión de responsabilidad que pueda alegar la persona jurídica generarán con toda seguridad disfunciones en la práctica. Por ello, es necesaria una interpretación correctiva a la luz de la Constitución de la República del Ecuador (en adelante CRE) del régimen de RPPJ que la convierta en operativa. A continuación, se dará ese marco de fundamentación.

\subsection{Argumento constitucional}

[...] la doctrina de la responsabilidad penal exclusiva de personas naturales va perdiendo su carácter de dogma y, por el contrario, se abre paso la corriente que demanda el establecimiento de responsabilidad penal a las personas jurídicas, pero en consideración a conductas o actuaciones que puedan ser atribuibles a aquellas, en virtud de su gestión [...] (Corte Constitucional del Ecuador, 2013, 027-13-DTI-CC, p. 24).

Otro de los inconvenientes que acarrea el modelo vicarial es su acusación de incompatibilidad con la Constitución. En Ecuador la crítica se ha centrado en la vulneración al principio de culpabilidad $^{28}$ en su manifestación de responsabilidad por el hecho propio. Es decir, en el derecho penal ecuatoriano, la responsabilidad de unos (persona física) no la pueden pagar otros (persona jurídica): la responsabilidad penal es personal y como consecuencia de lo que cada uno hace/omite. Además, el sancionar automáticamente a la persona jurídica cuando la física comete un delito crea una suerte de presunción iuris et de iure de culpabilidad que es incompatible igualmente con el principio de culpabilidad (exigencia de responsabilidad subjetiva) y -en el plano procesal- con la presunción de inocencia (art. 76.2 CRE). Por último, si el delito de la persona física es lo que genera tanto la responsabilidad de aquella como de la persona jurídica, se estaría vulnerando el non bis in idem ${ }^{29}$.

En España este debate ya se llevó a cabo, y dado que compartimos tanto los principios orientadores del derecho penal de tradicional europeo-continental y la presunción de

\footnotetext{
${ }^{26}$ Vid. infra nuestra interpretación correctiva para hacer efectivas las atenuantes.

${ }^{27}$ La variable se complica aún más en Ecuador debido a la escasa difusión de la RPPJ más allá de los círculos académicos: según un muestreo, los empresarios desconocen o yerran sobre la normativa, sobre todo respecto al compliance (cfr. Suqui Romero et al., 2018, p. 93).

${ }^{28}$ Derivado de los arts. 66.29.a), 66.5 CRE, y con cierto anclaje en la jurisprudencia constitucional, ej.: 027-13-DTI-CC, p. 24; 14-15-CN/19 (no 20 s.); sobre las manifestaciones ("subprincipios") del principio de culpabilidad, vid. 034-10-SEPCC, pp. $19 \mathrm{~s}$.

${ }^{29}$ Arts. 76.7.i) CRE, 5.9. COIP; Zavala Egas (2014, p. 85). Incluso sería cuestionable aplicar la RPPJ a pequeńas empresas (con escasa complejidad; aparte de la informalidad de la economía ecuatoriana), pues más allá del recurso formal a la diferente identidad de sujetos (física y jurídica), el sancionar a una persona jurídica de pequeñas dimensiones muchas veces equivale a sancionar de nuevo a las físicas que delinquieron. Ahora, la reforma ha incluido expresamente a las PYMES como destinatarias de la atenuante de compliance (art. 45.7.d) COIP); crítico además por los altos costos de implementación, Zambrano Pasquel (2021, p. 42).
} 
inocencia como garantía básica del proceso penal, interesa la reflexión que sobre el particular llevó a cabo la STS 261/2016, de 16 de marzo:

La Sala no puede identificarse [...] con la tesis de que, una vez acreditado el hecho de conexión, esto es, el particular delito cometido por la persona física, existiría una presunción iuris tantum de que ha existido un defecto organizativo [...]. Basta con reparar en algo tan elemental como que esa responsabilidad se está exigiendo en un proceso penal, las sanciones impuestas son de naturaleza penal y la acreditación del presupuesto del que derivan aquéllas no puede sustraerse al entendimiento constitucional del derecho a la presunción de inocencia. Sería contrario a nuestra concepción sobre ese principio estructural del proceso penal admitir la existencia de dos categorías de sujetos de la imputación. Una referida a las personas físicas, en la que el reto probatorio del Fiscal alcanzaría la máxima exigencia, y otra ligada a las personas colectivas, cuya singular naturaleza actuaría como excusa para rebajar el estándar constitucional que protege a toda persona, física o jurídica, frente a la que se hace valer el ius puniendi del Estado. (Tribunal Supremo español, 2016, p. 34)

Por ello, consideramos fundamental llegar a un consenso constitucional mínimo: si la persona jurídica no puede responder de manera absoluta/automática en derecho penal (prohibición de responsabilidad objetiva), entonces se le debe otorgar a esta una posibilidad de defensa razonable por una actuación que pudo controlar -en el "nosotros" empresarial-. Así, los partidarios del modelo de autorresponsabilidad ahuyentan al fantasma de la inconstitucionalidad construyendo una actuación propia de la persona jurídica: el defecto de organización. Ergo, lo que genera la RPPJ es la mala organización empresarial que no impida o dificulte los delitos de sus miembros cometidos en su beneficio.

Otorgar una defensa posible a la persona jurídica es además imprescindible, ya que la sanción predilecta del COIP es la extinción/disolución -más multa- (pena de muerte empresarial), la sanción más severa para una empresa que participa del tráfico jurídico con normalidad, y que incluso es difícilmente compatible con la finalidad de la pena en Ecuador (art. 52 COIP). Este punitivismo máximo que se desprende de la desproporción entre la extinción/disolución y la libertad de empresa ${ }^{30}$ (art. 66.15 CRE) debe ser restringida con una interpretación conforme a la Constitución (art. 13.1 COIP) que la reserve para los casos más graves $^{31}$ : a mayor gravedad de la sanción, mayores garantías sustantivas y procesales. Esto tiene como consecuencia que si la persona jurídica se beneficia asi sea de una atenuante, sería inconstitucional aplicar la extinción/disolución por vulnerar el principio de proporcionalidad sancionatoria (art. 76.6 CRE) ${ }^{32}$, pues el art. 54 COIP exige al juez individualizar la pena observando -entre otras- las circunstancias atenuantes. Después de todo, la razón de ser del principio de legalidad no es contraria a una interpretación como esta que beneficie al reo (cfr. a contrario arts. 13.3., 53 COIP).

Según este enfoque constitucional, se propone a continuación una solución conciliadora sobre el conflicto entre modelos de RPPJ en Ecuador.

\footnotetext{
${ }^{30}$ Así Schünemann (2014, pp. 16 s.) sobre un proyecto de ley de RPPJ del Land Nordrhein-Westfalen; en general, Roxin/ Greco (2020, $\$ 8$ párr. 58-63d).

${ }^{31}$ Vid. en Ávila Santamaría (2007) cómo los jueces penales están llamados a emplear principios constitucionales cuando la aplicación de la ley penal lleve a un resultado injusto.

${ }^{32}$ Mutatis mutandis y a fortiori: 025-16-SIN-CC (pp. 9-15).
} 


\section{3. ¿Auto- o heterorresponsabilidad?: ¿el vaso medio lleno o medio vacío?}

Ya apuntaba Nieto Martín en 2008 que la clasificación entre uno u otro sistema de RPPJ no tiene que ver con "modelos expresamente positivizados, sino con ideales reguladores” (p. 87). Ningún ordenamiento jurídico suele constar con un modelo en estado puro, sino que existe una tendencia hacia ellos (modelos mixtos). Todos los modelos legislativos en realidad tienen elementos que provienen del sistema vicarial y otros que los aproximan al de autorresponsabilidad.

¿Cuáles son esos elementos de cada modelo en Ecuador? Una característica innegable del modelo vicarial en el sistema ecuatoriano es la exigencia del cometimiento de un delito por parte de las personas físicas descritas en el art. 49 inc. 1 COIP. Igualmente, rasgos del modelo de autorresponsabilidad son que el art. 49 inc. 2 declara que la RPPJ es independiente de la responsabilidad de la persona física que intervenga en el delito, y que el art. 50 establezca que la RPPJ no se extingue ni modifica cuando haya concurrencia de responsabilidad con la persona física, incluso en los casos en que haya "circunstancias que afecten o agraven la responsabilidad o porque dichas personas han fallecido o eludido la acción de la justicia", o porque se extinga la responsabilidad de las personas físicas, o se dicte sobreseimiento $^{33}$. Además, si admitiésemos que en Ecuador rige un sistema vicarial sin más, tendríamos que aceptar que en los casos en que exista ausencia de culpabilidad en la persona física, no se podría castigar a la persona jurídica, pues ¿qué culpabilidad se puede transferir en estos casos?

En España, tras de una lucha entre modelos, voces en la academia abogan por una superación de esta distinción (Cigüela Sola y Ortiz de Urbina Gimeno, 2020, pp. 77 s.). ¿Debería aprender de esto Ecuador? ¿Por qué gastar ríos de tinta en una distinción que en lo esencial no ha rendido frutos en otros países, sino que ha servido para polarizar opiniones que en realidad tienen más en común de lo que parece?

En este sentido, el debate ecuatoriano sobre el modelo a seguir se desvanece cuando la mayoría de los que interpretan de lege lata un modelo vicarial de lege ferenda abogan por uno de autorresponsabilidad (López Cobeña, 2018, pp. 106 s.; Pacheco, 2019, pp. 203, 218). Un consenso saludable pasaría por patrocinar una interpretación constitucional del modelo y que además siga siendo preferible una previsión expresa sobre la exclusión de responsabilidad en aras a la seguridad jurídica ${ }^{34}$.

La autorresponsabilidad minima defiende una interpretación constitucional del art. 49 COIP que impida la transferencia de responsabilidad penal de manera objetiva de una persona física a una persona jurídica. Así, el fundamento de la RPPJ (su "delito corporativo") reside en que esta haya permitido o fomentado la comisión de delitos individuales en

\footnotetext{
33 Advertía la dicotomía ya Pozo Torres (2018, pp. 78 s.); Pazmiño Ruiz y Pozo Torres (2019, p. 103).

La cláusula de "inextinción" de responsabilidad en Ecuador (art. 50 inc. 2 COIP) es ambivalente: que no se extinga la RPPJ en casos de fusión, etc. no quiere decir necesariamente que la responsabilidad se traslade a la otra entidad -como sí se desprende del art. 130.2. CPe-. Acorde con un modelo de autorresponsabilidad mínima (vid. infra), se propone que en estos casos se atienda a la debida diligencia de la entidad: ej., en la fusión, si se cumplió con el deber de cuidado en los procedimientos de due diligence, la persona jurídica quedará exenta de responsabilidad (en Espańa, Ortiz de Urbina Gimeno, 2017, p. 265), máxime si el COIP la exige como uno de los requisitos de compliance (art. 49.11.), pues interpretarla como responsabilidad objetiva/automática en estos casos traería consigo graves consecuencias prácticas: una parálisis del mercado debido a una suerte de "ruleta rusa penal" que le obliga a la otra empresa a asumir la responsabilidad por un delito que no ha cometido uno sus miembros. En los casos de disolución/liquidación aparente (para eludir la pena) se deberá atender no a la forma jurídica sino a la realidad económicalempresarial de la entidad (similar al criterio del art. 298 trasantepenúlt. inc. COIP), esto es, a su continuidad de la actividad; igual en la transformación: lo que importa no es el cambio formal sino la realidad material; similar en la escisión: las entidades resultantes no son sino una división de la realidad económica de la entidad infractora (en España, Dopico Gómez-Aller, 2010, pp. 36 s.).

${ }^{34}$ Similar a lo ya previstos por el pre-legislador (vid. informe $1^{\circ}$ y $2^{\circ}$ debate, ley anticorrupción).
} 
su beneficio. Con ello, el mensaje constitucional que se traslada a la empresa a través de una interpretación correctiva de la legislación penal es: organízate bien para que los tuyos no delincan en tu beneficio.

Luego, si la empresa adopta medidas idóneas de prevención y control ex ante para intentar evitar que se cometan delitos, no debería tener responsabilidad penal si uno de sus empleados, agentes, directivos, etc. comete un delito en su beneficio en el ámbito empresarial, pues -en este caso- la persona física ha delinquido eludiendo las medidas de control implementadas por la persona jurídica precisamente para impedir el delito (demostraría su "debido control"). En este sentido, la persona física con su actuación delictiva no compromete a la organización empresarial, sino que ha intervenido como una suerte de tercero (outsider) que ha cometido un delito a pesar de que la empresa estaba bien organizada. En suma, no ha habido un defecto de organización.

La mera literalidad del art. 49 COIP es perjudicial para el orden constitucional ecuatoriano. Por ello es necesario una interpretación teleológica que concilie la finalidad político-criminal de la RPPJ con los principios irrenunciables del derecho penal que -como vimos- se desprenden de la Constitución ecuatoriana. Si la RPPJ, según la Corte Constitucional, tiene como objetivo "constitucionalmente válido" tutelar bienes jurídicos, garantizar la reparación integral sancionando tanto a personas físicas como jurídicas, y evitar la impunidad (001-18-SIN-CC, p. 21), estos fines no pueden ser alcanzados vulnerando las garantías constitucionales del derecho penal. Desde Roxin (1973, p. 40 y passim) conocemos con claridad que el derecho penal es más bien el instrumento por el cual los objetivos de política-criminal se convierten en la forma concreta de aplicación de la ley. En definitiva, el derecho penal de la persona jurídica debe acercar a la realidad los objetivos de política-criminal de la RPPJ. A ello se ha dedicado esta interpretación.

\section{Atenuantes y agravante}

La reforma ha introducido en el COIP cuatro circunstancias atenuantes de la RPPJ (art. 45.7.a-d) y una agravante (art. 47.21.). Las atenuantes tienen en común el ser posteriores al delito (ex post facto), excepto la de compliance. Para la rebaja de pena (reducción en un tercio del mínimo) sigue siendo necesaria la concurrencia de dos atenuantes y ninguna agravante según las reglas generales (art. 44). Antes de la reforma se propuso que en los casos en que hubiese una única atenuante se debería aplicar al menos la pena mínima prevista como una especie de atenuante incompleta ${ }^{35}$. Ahora, y como se expuso supra, cuando estemos frente a la "pena de muerte empresarial", por naturaleza inmodulable (todo o nada), la concurrencia así sea de una atenuante negaría su aplicación por respeto al principio de proporcionalidad sancionatoria (art. 76.6. CRE) y la exigencia de individualización de la pena judicial (art. 54 COIP). Solo así se puede corregir esta desproporción evidente y convertir en operativas las siguientes atenuantes.

La primera atenuante es la denuncia o confesión espontánea del delito. La espontaneidad debe entenderse de manera objetiva, sin atender a los motivos latentes (imposibles en la persona jurídica). La equiparación denuncia/confesión puede interpretarse como un rasgo más del modelo de autorresponsabilidad: si la responsabilidad de la persona jurídica es propia, esta puede o bien denunciar el delito cometido por la persona física o bien confesar su defecto de organización. Con la denuncia, la persona jurídica se intenta apartar del delito individual ("ella lo hizo, yo estaba bien organizada"). Con la confesión la persona jurídica reconoce su

\footnotetext{
${ }^{35}$ Vid. Pazmiño Ruiz y Pozo Torres (2019, pp. 116 s.). Incluso cabe preguntarse ¿̨por qué no rebajarla en un sexto (la mitad)?
} 
intervención en el delito ("estaba mal organizada"). En ambos casos, lo normal es que se siga una investigación para ambas, pues un presupuesto de la RPPJ es el delito individual.

Se exige además que la denuncia/confesión sea antes o durante la instrucción fiscal, siempre que la persona jurídica "no haya conocido formalmente sobre su inicio". Pues bien, la única forma de que una persona jurídica no haya sido notificada ("conocido formalmente") con la formulación de cargos sobre el inicio de la instrucción (art. 594.7 COIP) es si el fiscal durante esta etapa solicita vincular a otra/s persona/s jurídica/s (art. 593 COIP). En definitiva, la persona jurídica puede denunciar/confesar hasta antes de que tenga conocimiento formal de que se haya instruido un procedimiento penal en su contra.

La segunda atenuante es la colaboración con la investigación aportando elementos/ pruebas nuevas y decisivas inclusive durante la etapa de juicio. Estos elementos/pruebas (art. 454.1 COIP) deben ser a la vez novedosas y esenciales para el esclarecimiento de los hechos o la determinación de su relevancia jurídica. Una confesión posterior a la instrucción fiscal puede, empero, ser una prueba decisiva, excepto que ya exista prueba de cargo suficiente. Tampoco hay motivos para no aplicar la atenuante "trascendental" por colaboración (art. 46 COIP) a la persona jurídica cuando se cumplan sus requisitos, ni para que no se beneficie de una cooperación eficaz (art. 491 COIP).

La tercera atenuante es la reparación integral de los daños producidos por el delito antes de la etapa de juicio. Esto remite implícitamente al capítulo sobre la reparación integral, especialmente respecto a su finalidad y los mecanismos no excluyentes de reparación (arts. 77 s. COIP). La disminución del daño (especie de reparación parcial) no se encuentra prevista dentro de las atenuantes para la persona jurídica, empero, no hay motivos para no aplicar la atenuante genérica (art. 45.3 COIP) interpretada objetivamente.

La última atenuante es haber implementado un programa de cumplimento antes del delito, esto es, como instrumento preventivo. Se exige que el compliance esté a cargo o bien de un departamento/órgano autónomo en personas jurídicas de "mayor dimensión" o bien de una persona responsable en el caso de las PYMES (vid. n. 29), y que su funcionamiento se incorpore en todos los niveles de la organización. La persona a cargo del programa de cumplimiento es denominada comúnmente como compliance officer o encargado/oficial de cumplimiento (art. 49.9 COIP) ${ }^{36}$.

La reforma también ha incluido una agravante mixta alternativa para la persona jurídica. Esto significa que de las tres posibilidades basta con una para cumplir con la agravante. La primera alude a la reincidencia y por ello se remite implícitamente al art. 57 COIP. La segunda es valerse de otras personas jurídicas para cometer el delito. El valerse indica que la persona jurídica debe aprovecharse fraudulentamente de cierta situación (cfr. art. 42.1.b) COIP) respecto de las otras personas jurídicas que utiliza como instrumento con el fin de cometer un delito del catálogo de RPPJ. De la misma forma debe ser interpretada la última posibilidad de la agravante: la persona jurídica debe aprovecharse fraudulentamente de la normativa vigente para evadir su responsabilidad en el delito. Esto reafirma -y agrava- la cláusula de inextinción de RPPJ en los casos en que la persona jurídica se aproveche de cualquier subterfugio societario para evadir su responsabilidad (vid. nota 32).

\section{El compliance penal en Ecuador}

Los programas de cumplimiento penal se han incorporado al COIP tras la reforma. El art. 49.1. al 11. enumera los "requisitos mínimos" que debe contener este compliance, "sin per-

\footnotetext{
36 Sobre el compliance officer vid. Liñán Lafuente (2019); Pozo Torres (2020); con referencia al COIP, Cuenca Noboa et al (2019, pp. 279 s.).
} 
juicio de las disposiciones del Reglamento" y de "otras normas específicas". La frase "sin perjuicio" debe ser entendida en el sentido de que la normativa posterior pueda desarrollar estos mismos requisitos, pues si una norma extrapenal exige otros elementos de compliance que los mencionados en el COIP, sería inconstitucional por violación al principio de legalidad penal ${ }^{37}$, debido a que esta remisión no sería para "integrar" (complementar) la ley penal, sino para ampliarla (art. 5.1. COIP); más aún, no puede existir una ley penal fuera del COIP $\left(\right.$ art. 17) ${ }^{38}$. Ilustrativamente, si se deja que un reglamento exija otros requisitos de compliance, los cuales afectan al sí o no de la responsabilidad o atenuación, el Ejecutivo se convertiría en legislador, deformando así la división de poderes.

Así las cosas, el Legislativo ha introducido la valoración de la autorregulación como un factor mitigante de la RPPJ (Pazmińo Ruiz y Pozo Torres, 2019, pp. 106 ss.). El problema radica en que no se contempla expresamente al compliance idóneo ex ante como forma de excluir la RPPJ. Nuestra interpretación, siguiendo lo dicho supra, aboga por entender que cuando la empresa cuente con un compliance (no ya de papel), pero este no reúna los exigentes requisitos del art. 49 COIP, se podrá todavía beneficiar de la atenuación por el art. 45.7.d) COIP.

En España se vivió un proceso parecido. En la reforma del CPe de 2010, se reconocía como atenuante de la persona jurídica el haber establecido medidas de compliance eficaces para prevenir y descubrir los delitos que en un futuro pudieran cometerse, antes de la celebración del juicio oral. La diferencia es que esta atenuante se focaliza en el compliance ex post, es decir, se valoran los esfuerzos de la persona jurídica para mejorar su autorregulación y dificultar la comisión de delitos futuros una vez ocurrido el mismo, pero no se reconocía expresamente qué sucedía si el sistema se había implantado antes de la comisión de este. Ello, junto a la interpretación teleológica del artículo 31.bis CPe -sobre el debido control- llevó a la doctrina a defender que el compliance penal idóneo ex ante debía generar la exención de RPPJ al no haberse cometido el delito por una ausencia del debido control (léase: sin defecto de organización) por lo que la RPPJ carecería de fundamento (Juanes Peces y González Cuellar, 2010, p. 5; Liñán Lafuente, 2011, p. 57).

En la reforma de 2015, el legislador español especificó en su artículo 31.bis 2 CPe que la persona jurídica quedará exenta de responsabilidad penal si concurren cuatro circunstancias: a) que el órgano de administración haya adoptado un compliance penal adecuado ex antes; b) que la supervisión del funcionamiento y del cumplimiento del programa ha sido confiada a un órgano de la persona jurídica con poderes autónomos de iniciativa y control (en personas jurídicas de pequeñas dimensiones esta función podrá ser asumida por el órgano de administración); c) que los autores hayan cometido el delito eludiendo fraudulentamente el programa de cumplimiento; d) que no se haya producido una omisión o ejercicio insuficiente en las funciones de supervisión, vigilancia y control del órgano de supervisión (compliance officer). Así, se establece el carácter exoneratorio del compliance ex ante, siempre que no haya existido un negligente control por el órgano encargado al efecto.

Ello implica que, en la práctica, si no se demuestra que ha existido un déficit de organización por parte de la empresa, esta deba quedar exenta de responsabilidad. En un auto reciente, el Juzgado Central de Instrucción no 6 de la Audiencia Nacional de 10 de mayo de 2021 lo ha expuesto en los términos siguientes:

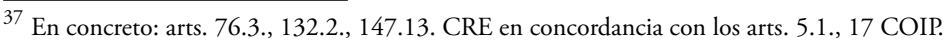

${ }^{38}$ Vid., sobre la ley penal en blanco, 26-13-IN/20, párr. 19; sobre la "colaboración reglamentaria", 009-17-SIN-CC, p. 17.
} 
De este modo, la responsabilidad penal de una persona jurídica exige tres requisitos positivos: un delito de los expresamente previstos; cometido por directivo o un empleado no adecuadamente controlado; y que reporte beneficios a la entidad, y uno negativo: que no exista un programa de cumplimiento que se pueda considerar adecuado o eficaz en un juicio ex ante (en un juicio ex post, siempre será ineficaz). (p. 7)

Tanto el COIP en su art. 49 como el CPe en su art. 31 bis.5. incorporan unos requisitos mínimos que han de cumplir los modelos de prevención de delitos. Se puede comprobar que el "núcleo" de ambos sistemas es similar, pues parten de la identificación de las actividades que provoquen riesgos penales (en la práctica, a través de un mapa de riesgos que relaciona la actividad empresarial con el riesgo penal) y el control de estos a través procedimientos de supervisión adecuados. Al fin y al cabo, de lo que se trata es de mantener controlados los focos de riesgo que deben ser prevenidos ${ }^{39}$. Junto a ello, se incorporan requisitos estructurales que debe contener el sistema de prevención: canal de denuncia, código ético (como requisito este sólo lo exige el COIP, aunque en la práctica en España se incorpora a todo plan de compliance como evidencia de su "cultura de cumplimiento"), sistema disciplinario interno frente a los incumplimientos, recursos financieros para el modelo de compliance, y verificación periódica del modelo.

El COIP hace referencia a "evaluaciones independientes" del modelo, por lo que se establece la necesidad de que un tercero valide el sistema. Este requisito no existe en España, y si bien se han generado normas de buenas prácticas sobre certificaciones del modelo de compliance penal (UNE 19.601) no existe la obligación de que este sea evaluado por un tercero independiente para que pueda desplegar sus efectos atenuatorios o exoneratorios ${ }^{40}$. Con todo, el juez penal no está vinculado a ninguna certificación como si de una suerte de prueba tasada se tratase; ciertamente, tampoco quiere decir que esta no pueda ser valorada como un indicio del correcto sistema de cumplimiento.

Por otro lado, en Ecuador se ha aprobado el "Reglamento para calificar y regular a los implementadores de programas de cumplimiento penal" 41 en donde se detallan los también exigentes requisitos (vid. anexos) que deben cumplir los implementadores de compliance penal para que puedan ser, entre otros, autorizados como tales por dicho Ministerio -además de incorporar obligaciones para los mismos-, lo cual genera otra sospecha de inconstitucionalidad: ¿̨acaso no se estaría limitando desproporcionadamente la libertad de contratación (art. 66.16. CRE)? En un caso análogo, la Corte Constitucional declaró que un reglamento vulneraba este derecho por el mero hecho de prohibir que la publicidad con fines comerciales pueda ser gratuita (7-15-IN/21, pp. 5-13); a fortiori: :puede el Ejecutivo decidir quién presta el servicio de implementación de compliance a empresas privadas y quién no? (arts. 3, 12 y passim del reglamento op. cit.).

Pese a todo, Ecuador ha querido dar un paso más en el reconocimiento de la importancia del compliance penal al regular la prestación del servicio de sus implementadores ${ }^{42}$. Por ello, llama la atención que la adopción de un exigente sistema de compliance ex ante no sea reconocido como causa de exención de la RPPJ de manera expresa, más si el Ejecutivo se ha preocupado de regular la calificación, autorización y registro dichos implementadores.

\footnotetext{
${ }^{39}$ Vid. Liñán Lafuente (2019, pp. 22-9).

${ }^{40} \mathrm{Y}$ esto ni siquiera es así en el caso chileno: vid. Matus Acuña (2017).

41 Acuerdo no MPCEIP-DMPCEIP-2021-0002 del Ministerio de Producción, Comercio Exterior, Inversión y Pesca, de 21 de enero de 2021.

42 Empero, ¿rige lo mismo para los evaluadores independientes? Evaluar es diferente a implementar.
} 
Todo ello avala la interpretación de la autorresponsabilidad minima expuesta supra, pues si una empresa se preocupa de establecer un compliance penal ex ante, invirtiendo recursos en adoptar una correcta autorregulación para prevenir y controlar los riesgos penales, en caso de que se cometa un delito en su beneficio, deberá ser valorada esa circunstancia hasta el punto de poder eximir la RPPJ si se concluye que no existió un déficit de control y que el delito fue cometido por la persona física eludiendo los controles adoptados por la persona jurídica para evitar el riesgo penal.

\section{Epílogo}

La opción del legislador, tanto ecuatoriano como español, de atribuir a la persona jurídica de responsabilidad penal provoca la necesidad de adaptar el sistema penal para que este nuevo sujeto no vea restringido sus derechos por el mero de hecho de tener una naturaleza distinta a la de la persona física. Si el Estado apuesta por este tipo política legislativa, debe asegurar que a todos los sujetos penalmente responsables se les aplique el derecho penal con estricto respeto a sus derechos constitucionales, pues de otro modo se retrocedería al castigo automático por el hecho ajeno, volviendo a oscuros periodos de la historia que se entendían por superados.

La inclusión de este nuevo sujeto obliga además a adaptar el sistema procesal para que los derechos fundamentales de los investigados puedan ser aplicados a la persona jurídica, acorde a su naturaleza. Estéril resulta una reforma penal sin la correspondiente adaptación procesal para dotar de contenido al nuevo sistema. Espańa tardó varios meses, desde que se incorporó la RPPJ, en adaptar su sistema procesal para que a la persona jurídica le fueran reconocidos todos los derechos procesales y se arbitrase una forma para que pudiese prestar declaración durante la fase de instrucción y tomar las decisiones, como parte procesal, que más le convengan. Ecuador aún no ha acometido esta reforma que se considera esencial para encajar el sistema de RPPJ en el ordenamiento jurídico ecuatoriano, por lo que debería emprenderla sin dilación si quiere evitar disfunciones que lesionen los derechos de las partes.

Concluimos el artículo con la siguiente reflexión: todos podríamos estar de acuerdo en que, si no se permite a un sujeto penalmente responsable ejercer una defensa plena en el proceso penal, estaríamos ante un sistema penal deficiente que causa la vulneración de los derechos fundamentales del acusado. Si ello resulta tan claro, ¿̨por qué no extraña tanto plantear supuestos de transferencia de responsabilidad penal de la persona física a la jurídica, con la merma de derechos que ello conlleva? La respuesta no es sencilla, y posiblemente radique en la imposibilidad material de que una persona jurídica actué por sí misma, pero ello no puede llevar a que nos conformemos con una solución que a todas luces resultaría aberrante si se aplicase a dos personas físicas. Si es injusto para una, lo ha de ser necesariamente para la otra. Quizás esta pregunta nos puede servir para enfocar el apasionante estudio de la RPPJ, partiendo siempre del respeto a los derechos constitucionales y sus derivaciones dogmáticas desde esta interpretación teleológica. Ni más, ni menos, es lo que hemos intentado transmitir en las líneas precedentes.

\section{Referencias bibliográficas}

Albán Gómez, A. E. (2015). Manual de Derecho Penal Ecuatoriano según el COIP. Parte General. Tomo I. Quito: Ediciones Legales EDLE. 
Araujo Correa, T. E., Herrera Pacheco, J. A., y Suqui Romero, G. Y. (2019). El compliance en tiempos de responsabilidad penal de las personas jurídicas en Ecuador. Revista Polo del Conocimiento 4(8), 285-297. https://polodelconocimiento.com/ojs/index. php/es/article/view/1147

Araujo Granda, M. P. (2014). La nueva teoría del delito económico y empresarial en el Ecuador: la responsabilidad penal de las personas jurídicas y el Código Orgánico Integral Penal. Quito: Corporación de Estudios y Publicaciones.

Ávila Santamaría, R. (2007). ¿Pueden los juzgadores penales inaplicar el Código Penal? (Reflexiones sobre el control constitucional de las leyes penales). Foro, Revista de Derecho (8), 49-70. https://revistas.uasb.edu.ec/index.php/foro/article/view/337/336

Basabe Serrano, S. (2003). Responsabilidad penal de las personas jurídicas desde la teoría de los sistemas (tesis de maestría). Quito: Universidad Andina Simón Bolívar, Sede Ecuador. http://hdl.handle.net/10644/219

Encalada Hidalgo, P. (2014). Teoría constitucional del delito y el Código Orgánico Integral Penal (tesis de maestría). Quito: Universidad Andina Simón Bolívar, Sede Ecuador. http://hdl.handle.net/10644/3745

Fernández Teruelo, J. G. (2020). Parámetros interpretativos del modelo español de responsabilidad penal de las personas jurídicas y su prevención a través de un modelo de organización o gestión (compliance): incluye un análisis de los modelos de responsabilidad penal de las personas jurídicas en México y Ecuador. Cizur Menor (Navarra): Aranzadi.

García Falconí, R. J. (2014). Código Orgánico Integral Penal Comentado. Tomo I: Arts. 1 al 78, $1^{\text {a }}$ ed. (hay $2^{a}$ ed.), Lima: ARA Editores.

García Falconí, R. J. y Alba Zurita, E. (2017). La responsabilidad penal de las personas jurídicas, especial enfoque al caso ecuatoriano. En Pérez-Cruz Martín, A-J. (dir.) y Neira Pena, A. (coord.). Proceso penal y responsabilidad penal de las personas jurídicas (375-399). Navarra: Aranzadi.

Gómez Martín, V. (2012). Falsa alarma: o por qué la Ley Orgánica 5/2010 no deroga el principio "societas delinquere non potest". En Mir Puig, S. y Corcoy Bidasolo, M. (dirs.). Garantías constitucionales y Derecho penal europeo (331-383). Madrid: Marcial Pons.

Gracia Martín, L. (2016). Crítica de las modernas construcciones de una mal llamada responsabilidad penal de la persona jurídica. Revista Electrónica de Ciencia Penal y Criminología 18(5), 1-95. http://criminet.ugr.es/recpc/18/recpc18-05.pdf

Juanes Peces, A. y González Cuellar Serrano, N. (2010). La responsabilidad penal de las personas jurídicas y su enjuiciamiento en la reforma de 2010. Medidas a adoptar antes de su entrada en vigor. Diario La Ley, no 7501. Disponible (con suscripción) en https://diariolaley.laleynext.es/content/Inicio.aspx

Koehler, M. (2015). Measuring the Impact of Non-Prosecution Agreements on Foreign Corrupt Practices Act Enforcement. University of California 49, Davis, 497-565.

Liñán Lafuente, A. (2011). El control preventivo de la responsabilidad penal de las personas jurídicas. En Albiñana García-Quintana, C. (coord.). Cuadernos de Derecho para Ingenieros 14: Cumplimiento normativo. Compliance (43-60). Madrid: La Ley.

- (2019). La responsabilidad penal del compliance officer. Cizur menor: Aranzadi.

López Cobeña, A. (2018). La responsabilidad penal de las personas juridicas: el nuevo paradigma de la legislación ecuatoriana en el COIP. Quito: Cevallos.

Matus Acuña, J. P. (2017). Sobre el valor de las certificaciones de adopción e implementación del modelo de prevención de delitos frente a la responsabilidad penal de las personas jurídicas. R.E.D.S. 11, 38-43. 
Mila, F. (2020). La responsabilidad penal de las personas jurídicas en el derecho ecuatoriano. Ius et Praxis 26(1), 149-170. https://dx.doi.org/10.4067/S0718-00122020000100149

Mir Puig, S. (2015). Las nuevas "penas" para personas jurídicas, una clase de penas sin culpabilidad. Foro FICP 2, 140-148.

Nieto Martín, A. (2008). La responsabilidad penal de las personas jurídicas: un modelo legislativo. Madrid: Iustel.

—. (2015). Autorregulación, "compliance" y justicia restaurativa. En Arroyo Jiménez, L. y Nierto Martín, A. (dirs.). Autorregulación y Sanciones (99-134), 2a ed., Cizur Menor: Aranzadi. Pacheco, M. E. (2019). Revisiones procesales para un compliance basado en el modelo de responsabilidad penal en el Ecuador. Revista CAP Jurídica Central 3(5), 181-226. https://doi.org/10.29166/cap.v3i5.2259

Páez Bimos, P. M. (2017). Los problemas en la imputación penal de las personas jurídicas en el Ecuador. REIB: Revista Electrónica Iberoamericana 11(1), 88-100.https:/www. urjc.es/images/ceib/revista_electronica/vol_11_2017_1/REIB_11_01_Art5.pdf

- (2021). Corrupción en el ámbito privado y malas prácticas corporativas: Aproximación al Buen Gobierno Corporativo y la Cultura de Cumplimiento Normativo. Quito: Cevallos.

Pazmiño Ruiz, J. R. y Pozo Torres, J. F. (2019). Responsabilidad penal de las personas jurídicas y compliance: caso Ecuador. Derecho Penal y Criminología 40(109), 89122. https://doi.org/10.18601/01210483.v40n109.04

Pozo Torres, J. F. (2018). Fundamentos de la responsabilidad penal de las personas jurídicas en Ecuador. Quito: Corporación de Estudios y Publicaciones.

- (2020). Compliance y posición de garante: imputación de hechos delictivos al compliance officer. Foro, Nueva época 23(1), 127-154.

Raza Castañeda, S. (2016). La función del compliance en el análisis de la responsabilidad penal de la persona jurídica. Revista CAP Jurídica Central 1(1), 221-276. https://doi. org/10.29166/cap.v1i1.1934

Robles Planas, R. (2011). Pena y persona jurídica: crítica del artículo 31 bis CP. Diario La Ley, no 7705. Disponible (con suscripción) en https://diariolaley.laleynext.es/content/Inicio.aspx

Rodríguez Moreno, F. (2020). Curso de Derecho Penal: Parte General. Tomo II. Teoría del Delito, 2a ed., Quito: Cevallos.

Roxin, C. (1973). Kriminalpolitik und Strafrechtssystem, 2. Auflage (Reprint 2012), Berlin: Walter de Gruyter.

Roxin, C./Greco, L. (2020). Strafrecht Allgemeiner Teil Band I: Grundlagen. Der Aufbau der Verbrechenslehre, 5. Auflage, München: C.H. Beck.

Schünemann, B. (2014). Die aktuelle Forderung eines Verbandsstrafrechts - Ein kriminalpolitischer Zombie. Zeitschrift für Internationale Strafrechtsdogmatik 1, 1-18.

Silva Sánchez, J-M., (2016). Fundamentos del Derecho penal de la empresa, 2a ed. Madrid: Edisofer.

Sun Beale, S. (2016). The Development and Evolution of the U.S. Law of Corporate Criminal Liability and the Yates Memo. Stetson Law Review 46, 41-69. https://core.ac.uk/ download/pdf/237216446.pdf

Suqui Romero, G. Y., Merchán Ramón, M., y Cando Pacheco, J. de D. (2018). Temores empresariales en tiempo de responsabilidad penal de las personas jurídicas. Revista Universidad y Sociedad 10(1), 85-95.

Tiedemann, K. (1996). La responsabilidad penal de las personas jurídicas. Anuario de derecho penal (J. Hurtado Pozo), 97-125. 
-. (2010). Manual de derecho penal económico: parte general y especial (coord. de la traducción: M.A. Abanto Vásquez). Valencia: Tirant lo Blanch.

Villegas García, M.A (2015). Los criterios de imputación de la responsabilidad criminal de las personas jurídicas y sus efectos en los Estados Unidos (tesis doctoral). Universidad Complutense de Madrid. https://eprints.ucm.es/id/eprint/33361/

Zambrano Pasquel, A. (2017). La responsabilidad penal de las personas jurídicas en debate. En Reyna Alfaro, M. (dir.), Coca Vila, I. y Uribe Manríquez, A. R. (coords). Compliance y responsabilidad penal de las personas jurídicas: Perspectivas comparadas (EE. UU., España, Italia, México, Argentina, Colombia, Perú y Ecuador) (pp. 285-314). México: Editorial Flores.

—. (2021). Responsabilidad penal de las personas jurídicas. El Compliance y la Imputación Objetiva. Biblioteca Virtual AZP. http://www.alfonsozambrano.com/

Zavala Egas, J. (2014). Responsabilidad penal de las personas juridicas en el sistema constitucional ecuatoriano (arts. 49 y 50 COIP) - Una guia teórica-práctica. Samborondón: Universidad de Especialidades Espíritu Santo.

\section{Sentencias}

Audiencia Nacional de España (2021). Auto del Juzgado Central de Instrucción no 6, de 10 de mayo.

Corte Constitucional del Ecuador (2010). Acción Extraordinaria de Protección. Sentencia no 034-10-SEP-CC.

-. (2013). Dictamen de Constitucionalidad de Tratados Internacionales. Sentencia no 027-13-DTI-CC.

-. (2017). Acción Pública de Inconstitucionalidad. Sentencia nº 009-17-SIN-CC.

-. (2018). Acción Pública de Inconstitucionalidad. Sentencia no 001-18-SIN-CC.

-. (2019). Consulta de Constitucionalidad de Norma. Sentencia no 14-15-CN/19.

- (2020). Acción Pública de Inconstitucionalidad. Sentencia no 26-13-IN/20.

-. (2021). Acción Pública de Inconstitucionalidad. Sentencia no 7-15-IN/21.

Corte Nacional de Justicia del Ecuador (2021). Juicio no 17282-2017-03592 COIP. Resolución nº 00043-2021.

Tribunal Supremo de Espańa (2016). STS 154/2016, de 29 de febrero.

—. (2016). STS 221/2016, de 16 de marzo.

-. (2016). STS 827/2016, de 3 de noviembre.

-. (2017). STS $121 / 2017$, de 23 de febrero.

-. (2017). STS 260/2017, de 6 de abril.

-. (2017). STS 455/2017, de 21 de junio.

-. (2017). STS 583/2017, de 19 de julio.

- (2017). STS 668/2017, de 11 de octubre.

\section{Legislación}

Asamblea Constituyente del Ecuador (2008). Constitución de la República del Ecuador. Registro Oficial n. 449, de 20 de octubre de 2008.

Asamblea Nacional del Ecuador (2012). Informe para primer debate del Proyecto de Código Orgánico Integral Penal, de 13 de junio 2012. 
—. (2013). Informe para segundo debate del Proyecto de Código Orgánico Integral Penal, de 4 de octubre de 2013.

—. (2021). Ley orgánica reformatoria del Código Orgánico Integral Penal en materia anticorrupción. Registro Oficial del Ecuador n. 392, de 17 de febrero de 2021.

-. (2021). Ley orgánica de Extinción de Dominio. Registro Oficial del Ecuador n. 392, de 17 de febrero de 2021. Registro Oficial de Ecuador n. 452, de 14 de mayo de 2021.

Congreso de Diputados de España. Ley Orgánica 10/1995, de 23 de noviembre, del Código penal (última actualización: 05.06.2021).

Ministerio de Producción, Comercio Exterior, Inversiones y Pesca del Ecuador (2021). Reglamento para calificar y regular a los implementadores de programas de cumplimiento penal, de 21 de enero 2021. MPCEIP-DMPCEIP-2021-0002.

Presidencia de la República del Ecuador (2021). Objeción parcial al proyecto de ley orgánica reformatoria del Código Orgánico Integral Penal en materia anticorrupción, de 15 de enero de 2021.

\section{Convenciones, informes y comunicados}

FMI (2020a). Informe de pais $n^{o}$ 20/150. Octubre 2020. https://www.finanzas.gob.ec/ wp-content/uploads/downloads/2020/11/SPA-Ecuador-2020-EFF-Bundle.pdf

—. (2020b). Comunicado de prensa no 20/302, de 30 de septiembre de 2020. https://www. imf.org/es/News/Articles/2020/10/01/pr20302-ecuador-imf-executive-board-approves-27-month-extended-fund-facility

GAFISUD (2011). Informe de evaluación mutua sobre lucha contra el lavado de activos y el financiamiento del terrorismo, de 15 de diciembre 2011. https://www.gafilat.org/ index.php/es/biblioteca-virtual/miembros/ecuador/evaluaciones-mutuas-7/131-ecuador-3era-ronda-2011/file

OECD (1997). Convención para combatir el cohecho de servidores públicos extranjeros en transacciones comerciales internacionales y documentos relacionados, de 21 de noviembre de 1997.

ONU (2003). Convención de las Naciones Unidad contra la Corrupción. Oficina contra la Droga y el Delito, 31 de octubre de 2003. 